\title{
Gallbladder polyps: evolving approach to the diagnosis and management
}

\section{Kook Hyun Kim}

Division of Gastroenterology and Hepatology, Department of Internal Medicine, Yeungnam University College of Medicine, Daegu, Korea

Received: March 28, 2020

Revised: April 26, 2020

Accepted: April 29, 2020

Corresponding author:

Kook Hyun Kim

Division of Gastroenterology and

Hepatology, Department of Internal

Medicine, Yeungnam University

College of Medicine, 170

Hyeonchung-ro, Nam-gu, Daegu

42415, Korea

Tel: +82-53-620-3576

Fax: +82-53-654-8386

E-mail:kimkh@yu.ac.kr
Gallbladder (GB) polyp is a mucosal projection into the GB lumen. With increasing health awareness, GB polyps are frequently found using ultrasonography during health screening. The prevalence of GB polyps ranges between $1.3 \%$ and $9.5 \%$. Most patients are asymptomatic and have benign characteristics. Of the nonneoplastic polyps, cholesterol polyps are most common, accounting for $60 \%-70 \%$ of lesions. However, a few polyps have malignant potential. Currently, the guidelines recommend laparoscopic cholecystectomy for polyps larger than $1 \mathrm{~cm}$ in diameter due to their malignant potential. The treatment algorithm can be influenced by the size, shape, and numbers of polyps, old age (>50 years), the presence of primary sclerosing cholangitis, and gallstones. This review summarizes the commonly recognized concepts on GB polyps from diagnosis to an algorithm of treatment.

Keywords: Cholecystectomy; Diagnostic imaging; Gallbladder diseases; Gallbladder neoplasms; Polyps

\section{Introduction}

Gallbladder (GB) polyps are defined as mucosal projection of the GB wall into the lumen [1]. Recently, with the easy availability of ultrasonography (US) and the increasing awareness of physical checkup, the detection of GB polypoid lesion is steadily on the rise [2]. Most GB polyps are incidentally found and asymptomatic. Although benign lesions are overwhelming, some can be transformed into malignant. Polyps more than $1 \mathrm{~cm}$ in size and adenomatous polyps are of clinical importance due to the risk of cancerous change. The prevalence of GB polyps ranges from $1.3 \%$ to $9.5 \%$, with geographical differences [3-6]. A Korean data demonstrated that the prevalence of GB polyps in Korea ranges from $2.2 \%$ to $9.9 \%$, which is similar to other studies $[7,8]$. The guidelines for the diagnosis and treatment of GB polyps have remained unchanged for a while. In this review, the diagnosis, classification, natural history, and algorithm for the management of GB polyps will be described.

\section{Imaging modalities for the diagnosis of gallbladder polyps}

GB polyps are generally detected using US, followed infrequently by abdominal computed tomography (CT), magnetic resonance imaging (MRI), and positron emission tomography (PET) [9]. US is noninvasive, safe, easily accessible, and less costly; therefore, it is the primary choice in the diagnosis of GB polyps. The sonographic features of GB polyps are hyperechoic lesions protruding into the GB lumen, absence of post-acoustic shadow, and lack of positional change of lesions (Fig. 1). Under the supine with/or decubitus position, the lesion should be scanned for better visualization of polyps. Sometimes, the body habitus can affect the image quality. It is crucial to identify the size, number, and shape of polyps, GB wall thickening, and presence of gallstones. During US examination, however, gallstones smaller than $5 \mathrm{~mm}$ cannot be distinguished between polyps and stones in real practice

Copyright (C) 2021 Yeungnam University College of Medicine

This is an Open Access article distributed under the terms of the Creative Commons Attribution Non-Commercial License (http://creativecommons.org/licenses/by-nc/4.0/) which permits unrestricted non-commercial use, distribution, and reproduction in any medium, provided the original work is properly cited. 


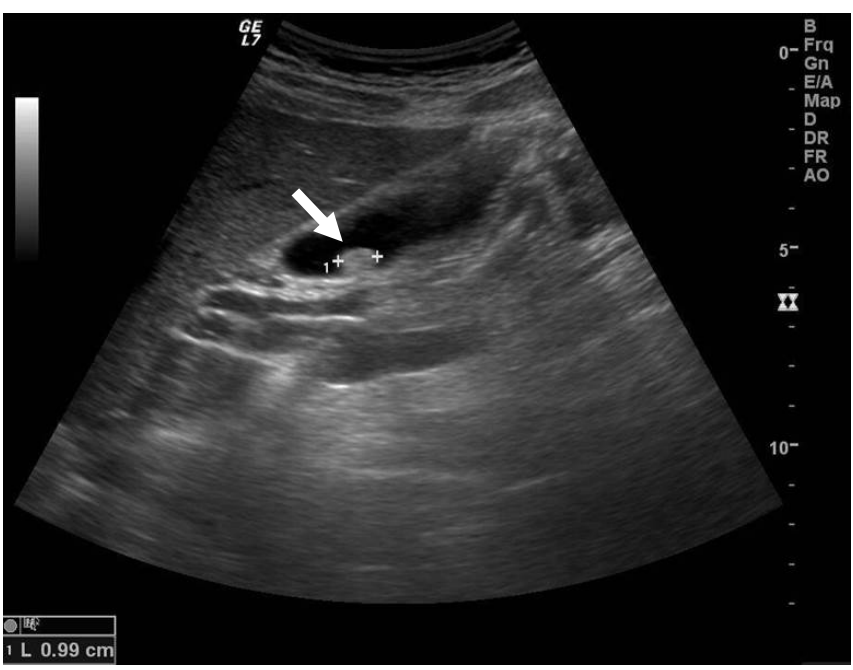

Fig. 1. Ultrasonography shows a polypod lesion (arrow) in the gallbladder. It measured $9.9 \mathrm{~mm}$ in maximal diameter and was not mobile regardless of the positional change. Pathologically, it was confirmed as adenoma.

$[10,11]$. Sometimes, the presence of biliary sludge, or small stones $(<5 \mathrm{~mm})$, can be mistaken as GB polyps $[12,13]$.

With the increasing use of endoscopic ultrasonography (EUS) in the gastrointestinal field, it is opted for detailed GB structures and augmenting the diagnostic accuracy of GB polyps. EUS is favorable, in particular, in patients who are obese or harbor bowel gas, because the probe is proximally positioned and scanning is performed from the duodenum. The sensitivity and specificity of EUS for carcinoma diagnosis were $91.7 \%$ and $87.7 \%$, respectively [14]. A Japanese group has proposed that an EUS scoring system based on polyp size, internal echo, and hyperechoic spotting may be a useful parameter for differentiating between neoplastic and nonneoplastic polyps, with high sensitivity (77.8\%) and specificity (82.7\%) [15]. Additionally, EUS can be an alternative in cases of diagnostic difficulty of GB polyps by abdominal US. However, the differential diagnosis between adenomatous polyps and cholesterol polyps based on EUS or US is still challenging because morphology and echo patterns are alike. Recently, contrast-enhanced harmonic EUS (CEH-EUS) was introduced to differentiate between GB adenomas and cholesterol polyps [16]. Following injection of contrast agents of microbubbles into the vessel, CEH-EUS can detect signals scattering from microbubbles because harmonic components derived from microbubbles are integer multiples of the fundamental frequency and higher than those from tissue [17]. Sensitivity and specificity of CEH-EUS for the differential diagnosis of GB adenomas from cholesterol polyps were $75.0 \%$ and $66.6 \%$, respectively [18]. In addition, an irregular vessel pattern by $\mathrm{CEH}$ -
EUS can enhance the diagnostic power with sensitivity and specificity of $90.3 \%$ and $96.6 \%$, respectively [19].

Other imaging modalities including CT, fluorine-18-labeled fluorodeoxyglucose ( ${ }^{18} \mathrm{~F}$-FDG) PET-CT, and MRI are occasionally collaborative to enhance the diagnostic power in cases of suspicious GB malignancy or cancer staging $[20,21]$. CT scans are considered as first-line modality for symptomatic patients. Although CT has lower sensitivity for the detection of small polyps, it is valuable for the preoperative evaluation of GB malignancy $[22,23]$. The role of PET scan is not fully defined yet. ${ }^{18}$ F-FDG PET-CT is usually used for staging of known or suspected GB cancer, but it is not tumor specific. Benign inflammatory GB lesions can also show false-positive on PET image [24]. The diagnostic power and limitations of MRI are similar to those of CT [25]. In particular, MRI is highly useful in the evaluation of tumor infiltration because of its high sensitivity of detection and evaluation of the primary lesion [26].

\section{Classification of gallbladder polyps}

Polypoid GB lesions are mainly categorized as benign and malignant. Specifically, benign lesions are divided into neoplastic and nonneoplastic (Tables 1,2) [1,27-29]. Most benign lesions are regarded as nonneoplastic. Cholesterol polyps, inflammatory polyps, and adenomyomas belong to nonneoplastic lesions; however, adenoma is classified as a neoplastic lesion. Abdominal US alone cannot determine whether it is a neoplastic or nonneoplastic polyp. Therefore, once GB polyps are incidentally identified using US, surgical treatment is frequently being considered if the size is larger than $1 \mathrm{~cm}$.

\section{Nonneoplastic polyps}

Nonneoplastic polyps have been identified based on the radiologic image, surgery, and pathologic findings (Table 1). The most common histologic types of nonneoplastic polyps are cholesterol polyps (60\%-90\%), followed by adenomyomas (25\%-40\%), and inflammatory polyps (10\%) [9]. However, in the study of Taskin et al. [29], fibromyoglandular polyps are the most common type (48\%) of nonneoplastic GB polyps.

\section{1) Cholesterol polyps}

Cholesterol polyps are most common nonneoplastic polyp, accounting for $60 \%-90 \%$ of lesions $[12,30]$. They are formed as a sequence of phagocytosis of cholesterol ester, triglyceride, and esterified sterols by macrophage located in the lamina propria, covering the columnar epithelium with foamy histiocytes. It is understood that their gradual accumulation develops as a result of cho- 
Table 1. Nonneoplastic gallbladder polyps

\begin{tabular}{|c|c|c|c|c|c|}
\hline Nonneoplastic polyp & Mean size $(\mathrm{mm})$ & Radiologic finding & Pathologic finding & $\begin{array}{c}\text { Number } \\
\text { (single/multiple, \%) }\end{array}$ & Frequency (\%) \\
\hline Inflammatory polyp & $<10$ & $\begin{array}{l}\text { US: variable echogenicity } \\
\text { (iso-, hypo-, or hyper-) }\end{array}$ & $\begin{array}{l}\text { Pseudopapillary fronds with reactive mu- } \\
\text { cosal changes, inflammation, and } \\
\text { increased vascularity }\end{array}$ & Usually multiple & 10 \\
\hline Fibromyoglandular polyp & $4.3(2-13)$ & $N A$ & $\begin{array}{l}\text { Broad-based polyps } \\
\text { Lobular units of small glands } \\
\text { Fibroblastic and/or muscular stroma }\end{array}$ & $\begin{array}{l}\text { Single (56) } \\
\text { Multiple (44) }\end{array}$ & 48 \\
\hline
\end{tabular}

US, ultrasonography; MRI, magnetic resonance imaging; NA, not available.

Table 2. Neoplastic gallbladder polyps

\begin{tabular}{|c|c|c|c|c|c|}
\hline Neoplastic polyp & Mean size $(\mathrm{mm})$ & Radiologic finding & Pathologic finding & $\begin{array}{c}\text { Number } \\
\text { (single/multiple, \%) }\end{array}$ & Frequency (\%) \\
\hline \multicolumn{6}{|l|}{ Benign tumor } \\
\hline \multicolumn{6}{|l|}{ Epithelial tumor } \\
\hline Adenoma & $7(5-20)$ & $\begin{array}{l}\text { US: isoechoic sessile or } \\
\text { pedunculated }\end{array}$ & $\begin{array}{l}\text { Sessile or pedunculated benign } \\
\text { glandular structures }\end{array}$ & Mainly single & $4-8.9$ \\
\hline $\begin{array}{l}\text { ICPN with low- and high-grade } \\
\text { intraepithelial neoplasia }\end{array}$ & $>20$ & NA & $\begin{array}{l}\text { A distinct polypoid mass, in- } \\
\text { traluminal papillary growth, } \\
\text { with low- and high-grade } \\
\text { dysplasia }\end{array}$ & $\begin{array}{l}\text { Single (82) } \\
\text { Multiple (18) }\end{array}$ & $0.5-0.8$ \\
\hline \multicolumn{6}{|l|}{ Mesenchymal tumor } \\
\hline Leiomyoma/lipoma & NA & NA & NA & NA & NA \\
\hline \multicolumn{6}{|l|}{ Malignant tumor } \\
\hline \multicolumn{6}{|l|}{ Epithelial tumor } \\
\hline Adenocarcinoma & $>10$ & $\begin{array}{l}\text { US: a wide polyp base, } \\
\text { thickening of wall } \\
\text { (>3 mm), a polypoid } \\
\text { mass projecting intra- } \\
\text { luminally }\end{array}$ & $\begin{array}{l}\text { Mainly papillary form; densely } \\
\text { cellular papillary fronds pro- } \\
\text { truding into the lumen, with } \\
\text { infiltrative growth }\end{array}$ & Mainly single & $\begin{array}{c}0.6-1.7 \\
\text { (80\% of gallbladder } \\
\text { malignancy) }\end{array}$ \\
\hline $\begin{array}{l}\text { ICPN with associated invasive } \\
\text { carcinoma }\end{array}$ & $>20$ & & $\begin{array}{l}\text { Intraluminal growth; mainly } \\
\text { papillary growth pattern and } \\
\text { stromal invasion }\end{array}$ & $\begin{array}{l}\text { Single (78) } \\
\text { Multiple (22) }\end{array}$ & $0.5-0.8$ \\
\hline \multicolumn{6}{|l|}{ Mesenchymal tumor } \\
\hline Leiomyosarcoma & NA & NA & NA & NA & $\begin{array}{c}<0.1 \text { (1\%-2\% of } \\
\text { gallbladder malig- } \\
\text { nancy) }\end{array}$ \\
\hline
\end{tabular}

US, ultrasonography; ICPN, intracholecystic papillary neoplasm; NA, not available.

lesterol metabolism disruption [11,31]. These polyps are more prevalent in middle-aged women, with sizes less than $10 \mathrm{~mm}$ [31]. At US, cholesterol polyps appear as small and round lesions that are attached to the wall, characterized as "ball on the wall" sign [23]. Cholesterol polyps have a distinctive cauliflower configuration, which is commonly lined by single-layered normal epitheli- um with underlying thick, cholesterol-laden, or widened edematous cores (Fig. 2) [29]. In cholesterolosis, the mucosa acquires a velvety pattern with yellow-green-colored papillary structures with a diameter of less than $1 \mathrm{~mm}$. 

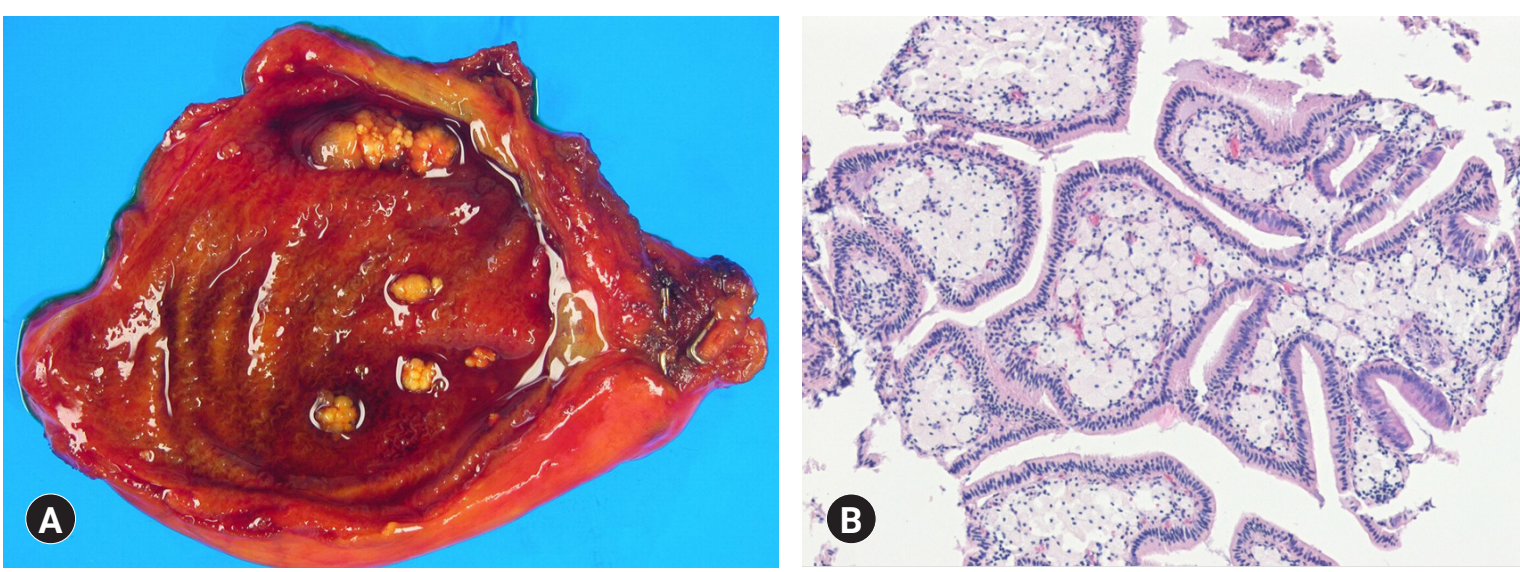

Fig. 2. Cholesterol polyp in a 55-year-old woman. (A) Grossly, the gallbladder shows multiple yellowish polyps in the lumen. (B) Microscopically, cholesterol polyps are characterized by cauliflower architecture. Numerous cholesterol-laden macrophages are present (hematoxylin and eosin stain, x100).
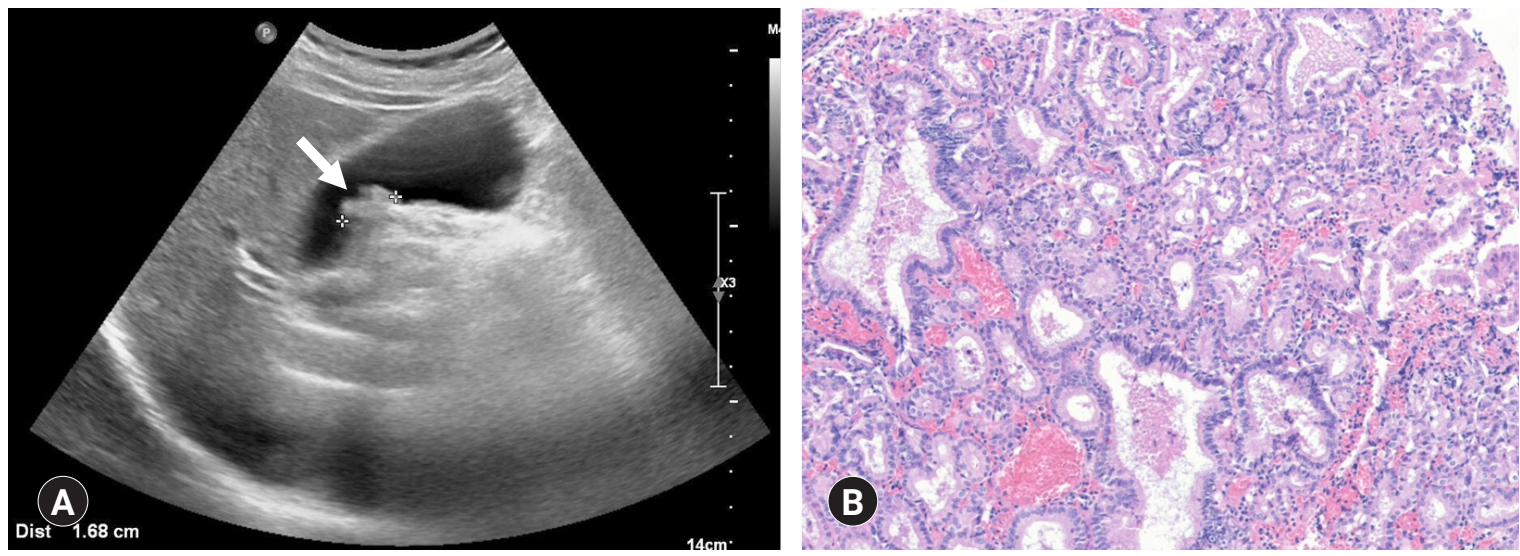

Fig. 3. Adenomatous gallbladder polyp in a 69-year-old man. (A) Ultrasonography shows a sessile polyp (arrow) with a wide base that was immobile and lacks an acoustic shadow. The polyp measured $16.8 \mathrm{~mm}$ in maximal diameter. (B) Microscopically, the adenoma is composed of closely packed, pyloric-type glands lined by mucin-containing cuboidal cells (hematoxylin and eosin stain, x100).

\section{2) Adenomyomas}

It is known that these lesions are formed during cholecystitis events as a result of mucosal hyperplasia or thickening of the muscular tissue [11]. Mucosal hyperplasia can lead to adenomyoma with the formation and branching of Rokitansky-Aschoff sinuses in the muscular layer of the GB. These are commonly classified into three types based on the morphology: fundal (localized), segmental (annular), and diffuse (generalized) types. A typical sonographic finding is the presence of reverberation or "comet tail" artifact posterior to the lesion [22]. Particularly, the segmental type mimics the hourglass configuration due to the concentric circumferential thickening of the GB wall [20]. At MRI, the Rokitansky-Aschoff sinuses create a "pearl necklace" sign of multiple round spaces on $\mathrm{T} 2$-weighted images, which has $92 \%$ specificity for adenomyomatosis $[25,32]$.

\section{3) Inflammatory polyps}

Inflammatory polyps reportedly constitute $10 \%$ of benign polyps, measuring less than $10 \mathrm{~mm}$ in diameter [21]. They occur as a secondary change following chronic inflammation and gallstone formation. Gradual and long-lasting precipitation of cholesterol results in subsequent mucosal irritation of the GB. It is presumed that the inflammatory process involving lymphocytes and plasma cells is attributed to chronic inflammation, finally ensuing granulation and fibrous tissue formation [20]. Consequently, pathology shows pseudopapillary fronds with reactive mucosal changes, inflammation, and increased vascularity [23]. Little is known about the imaging features of these polyps. At US, it presents a variety of echoic patterns, including iso-, hypo-, and hyper-echogenicity [33]. 


\section{Neoplastic polyps}

The most important neoplastic polyps are adenoma and adenocarcinoma. However, there have been case reports of mesenchymal tumors, such as leiomyosarcoma, leiomyomas, and lipomas $[9,21,34]$.

\section{1) Adenoma}

GB adenomas occur in 4\%-8.9\% of all GB polyps (Table 2) $[21,30,34,35]$. The adenoma can be sessile, pedunculated, or polypoid and usually measures from 5 to $20 \mathrm{~mm}$. At US, the adenomatous polyp is characterized by an isoechoic appearance and usually solitary (Fig. 3) [23,25]. Its malignant potential remains controversial. Unlike the colon, in which the adenoma-carcinoma pathway is the well-established mechanism of carcinogenesis, the dysplasia-carcinoma sequence is believed to play a major role in GB carcinogenesis [36-39]. Its plausible explanation is that chronic inflammation can lead to dysplasia, which ultimately develops into cancer. Most adenomas are incidentally found, similar to other polyps. Unfortunately, there is no reliable imaging modality to differentiate GB adenoma from adenocarcinoma yet.

\section{2) Intracholecystic papillary neoplasms}

Intracholecystic papillary neoplasms (ICPNs) are very rare, occurring in $0.5 \%-0.8 \%$ of all cholecystectomies [ 40,41$]$. Little is known about their clinicopathological trait and natural history due to the lack of standardized terminology among pathologists or published data. ICPNs are mass-forming neoplasms $(\geq 1 \mathrm{~cm})$, which are the GB counterparts of the pancreatic intraductal papillary mucinous neoplasms and the biliary ductal intraductal papillary neoplasms [40]. Grossly, ICPNs are featured by single or multifocal large pedunculated or sessile exophytic cauliflower-like configuration or polypoid projections [40]. Microscopic image shows a variety of cytological atypia, architectural atypia with papillary and tubular patterns [41]. The frequency of high-grade dysplasia and associated invasive carcinoma was significantly higher in those with papillary growth pattern than in tubular ones.

\section{3) Adenocarcinoma}

It is the most common malignant GB polyp and is more frequently found in women and elderly patients [23]. Histopathologically, the most common histologic types of GB cancers are adenocarcinoma. Based on the architecture and cytological morphology, it can be classified into three types: well, moderately, and poorly differentiated [11]. Of the several subtypes, the papillary form is the most common and presents densely cellular papillary fronds, which project into the GB lumen [9]. On US, it usually has a solitary polyp larger than $10 \mathrm{~mm}$ with a wide base [42]. PET-CT has been a valuable modality for the differential diagnosis of GB malignancy $[43,44]$. Koh et al. [44] reported that the sensitivity of ${ }^{18}$ F-FDG PET was $75 \%$ for the diagnosis of GB carcinoma.

\section{Natural course of gallbladder polyps}

To date, the natural history and pathogenesis of GB polypoid lesions are still scarce. A meta-analysis about a 7-year follow-up of GB polyps revealed a size progression in $7.6 \%$, no interval changes in $45.1 \%$, shrinkage in $7 \%$, and complete disappearance of polyps in 7.6\% [45]. An 11-year follow-up conducted by Heitz et al. [46] demonstrated an increase in $35.7 \%$, no change of polyps in $14.3 \%$, and a decrease in size in 50\%. Park et al. [42] reported that $75 \%$ of polyps were unchanged, $15 \%$ increased, and $10 \%$ decreased in size during a median 60-month follow-up. Colecchia et al. [47] reported that polyps were $91 \%$ unchanged, $5.7 \%$ increased, and $3.8 \%$ decreased in size during a 5-year follow-up. However, no clinical data are available on the duration of follow-up of small polyps $(<1 \mathrm{~cm})$. Some studies have described that $94 \%$ of polyps with diameter less than $1 \mathrm{~cm}$ were benign $[10,48]$. Colecchia et al. [47] showed that there were no symptoms and/or morphological changes of small-sized polyps during the 5-year follow-up.

\section{Management of gallbladder polyps}

As the presence of a polyp larger than $10 \mathrm{~mm}$ in diameter is accepted as having malignancy potential, cholecystectomy is currently the treatment of choice [12,49-51]. However, there is still no agreement on the management of GB polyps less than $10 \mathrm{~mm}$ in diameter. Recently, the European Society of Gastrointestinal and Abdominal Radiology proposed a treatment algorithm for GB polyps [49]. A small polyp rarely causes any symptoms in the clinical setting. Nevertheless, laparoscopic resection is recommended if there is no definite cause for upper abdominal pain and the patient is eligible for cholecystectomy (Fig. 4) [11,49]. There are other predictive risk factors for the physician to consider for appropriate management. The risk factors of GB malignancy are old age ( $>50$ years), history of primary sclerosing cholangitis (PSC), and the presence of gallstones and sessile polyp [49]. For those with nonneoplastic and polypoid lesions smaller than 10 $\mathrm{mm}$, a "wait and see" policy and regular follow-up are warranted [11]. Among patients with small polyps, cholecystectomy is recommended if they have the aforementioned risk factors [49]. Likewise, cholecystectomy is advised in cases of rapid polyp growth. 


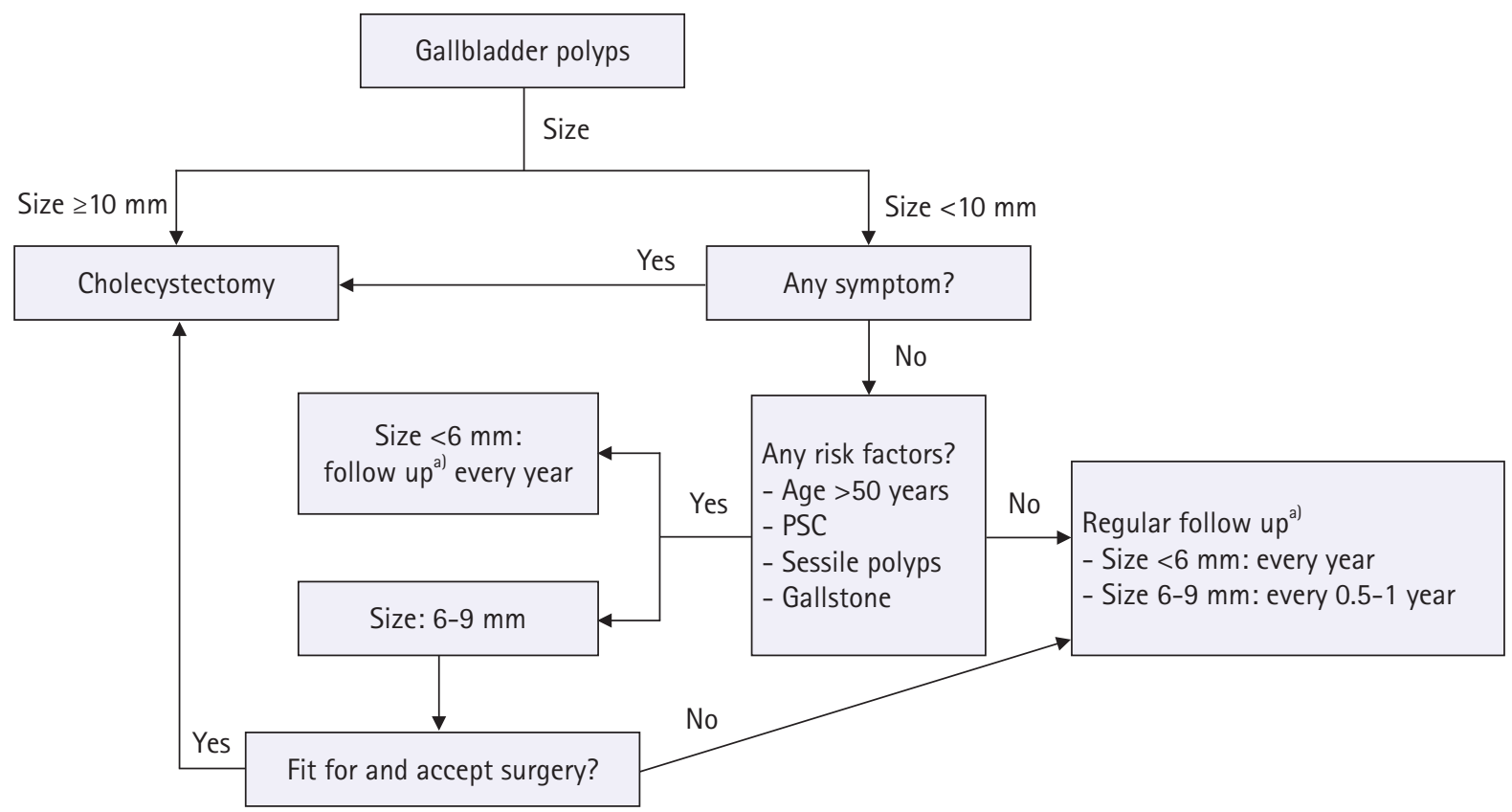

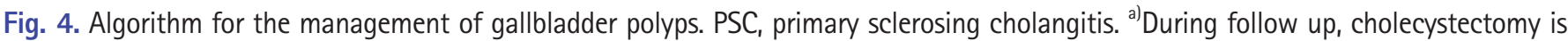
advised if the polyp size increases, however, follow up is unnecessary if the polyp disappears.

\section{Age}

The risk of malignant change of a GB polyp increases with age. Several studies have different cutoff values for malignancy risk. Kwon et al. [52] reported that age over 60 years $(p=0.021$; odds ratio $[\mathrm{OR}], 8.16)$ is a risk factor for malignant polyps. However, the age 50 is usually indicated as a risk factor threshold for cholecystectomy. A systemic review indicated that if the patient is older than 50 years of age, the odds of malignancy increase by 11.83 $[12,53,54]$. Bhatt et al. [53] suggested that when the polyp was smaller than $10 \mathrm{~mm}$ and age was over 50 , the probability of malignancy was $20.7 \%$, in which resection has been recommended.

\section{Numbers}

The relationship of malignant potential between single and multiple polyps has not been established yet. Several studies did not prove any association between a solitary polyp and high risk of malignancy. Meanwhile, in a systematic review by Bhatt et al. [53], a solitary polyp alone increased the odds of malignancy by a factor of 2.05. Furthermore, a solitary polyp in a patient over 50 years old escalated the probability of malignancy by $24.25 \%$.

\section{Sessile polyps}

A sessile morphology is more predominant in malignant polyps. GB cancer usually arises in situ from a flat, dysplastic epithelium, which explains the malignant potential of the sessile shape [52,55]. Kwon et al. [52] demonstrated that sessile polyps in- crease the risk of malignancy by a factor of 7.70 ( $95 \%$ confidence interval [CI], 2.48-23.95). Likewise, a systemic review by Bhatt et al. [53] revealed that the sessile shape in a GB polyp was identified as an independent risk factor of malignancy by a factor of 7.32 (95\% CI, 4.18-12.82).

\section{Gallstones}

A few studies have proposed that gallstones may be a risk factor for malignancy in GB polyps [56]. However, the risk of malignancy of polyps when combined with gallstones is relatively low and evidence is weak. Although Aldouri et al. [56] suggested that the presence of gallstones was an independent risk factor, Park et al. [42] did not reveal any connection between concurrent gallstones and malignancy.

\section{Primary sclerosing cholangitis}

PSC is a well-established risk factor for a GB polyp malignancy, requiring cholecystectomy regardless of the polyp size [57]. Said et al. [58] revealed that GB polyps were found in $6 \%(18 / 286)$ of patients, GB malignancy in 56\% (10/18), and dysplasia in 9\% [58]. An inflammation-dysplasia-carcinoma sequence might be the plausible elucidation, which was similar to that of cholangiocarcinoma in PSC and colorectal cancer in ulcerative colitis [58-60]. 


\section{Conclusion}

Of the imaging modalities, US played a pivotal role in diagnosing GB polyps. A diameter greater than $10 \mathrm{~mm}$ is undoubtedly the most important risk factor of malignancy, requiring cholecystectomy. It is currently warranted to take the "wait and see" policy at a regular interval, rather than resection, for incidental polyps of 6-9 $\mathrm{mm}$ in size. Other risk factors, including any symptoms, concurrent gallstones, age $>50$ years, sessile polyps, and PSC, should be considered in determining the treatment plan.

\section{Acknowledgments}

\section{Conflicts of interest}

No potential conflict of interest relevant to this article was reported.

\section{ORCID}

Kook Hyun Kim, https://orcid.org/0000-0001-7786-7882

\section{References}

1. Christensen AH, Ishak KG. Benign tumors and pseudotumors of the gallbladder: report of 180 cases. Arch Pathol 1970; 90:423-32.

2. Moriguchi H, Tazawa J, Hayashi Y, Takenawa H, Nakayama E, Marumo F, et al. Natural history of polypoid lesions in the gall bladder. Gut 1996;39:860-2.

3. Lin WR, Lin DY, Tai DI, Hsieh SY, Lin CY, Sheen IS, et al. Prevalence of and risk factors for gallbladder polyps detected by ultrasonography among healthy Chinese: analysis of 34669 cases. J Gastroenterol Hepatol 2008;23:965-9.

4. Jørgensen T, Jensen KH. Polyps in the gallbladder: a prevalence study. Scand J Gastroenterol 1990;25:281-6.

5. Segawa K, Arisawa T, Niwa Y, Suzuki T, Tsukamoto Y, Goto H, et al. Prevalence of gallbladder polyps among apparently healthy Japanese: ultrasonographic study. Am J Gastroenterol 1992; $87: 630-3$.

6. Chen CY, Lu CL, Chang FY, Lee SD. Risk factors for gallbladder polyps in the Chinese population. Am J Gastroenterol 1997;92:2066-8.

7. Kim SY, Lee HS, Lee YS, Chung KW, Jang BK, Chung WJ, et al. Prevalence and risk factors of gallbladder polyp in adults living in Daegu and Gyeongbuk provinces. Korean J Gastroenterol 2006;48:344-50.

8. Choi YS, Do JH, Seo SW, Lee SE, Oh HC, Min YJ, et al. Prevalence and risk factors of gallbladder polypoid lesions in a healthy population. Yonsei Med J 2016;57:1370-5.

9. Mellnick VM, Menias CO, Sandrasegaran K, Hara AK, Kielar AZ, Brunt EM, et al. Polypoid lesions of the gallbladder: disease spectrum with pathologic correlation. Radiographics 2015; 35:387-99.

10. Chattopadhyay D, Lochan R, Balupuri S, Gopinath BR, Wynne KS. Outcome of gall bladder polypoidal lesions detected by transabdominal ultrasound scanning: a nine year experience. World J Gastroenterol 2005;11:2171-3.

11. Dilek ON, Karasu S, Dilek FH. Diagnosis and treatment of gallbladder polyps: current perspectives. Euroasian J Hepatogastroenterol 2019;9:40-8.

12. Lee KF, Wong J, Li JC, Lai PB. Polypoid lesions of the gallbladder. Am J Surg 2004;188:186-90.

13. Zielinski MD, Atwell TD, Davis PW, Kendrick ML, Que FG. Comparison of surgically resected polypoid lesions of the gallbladder to their pre-operative ultrasound characteristics. J Gastrointest Surg 2009;13:19-25.

14. Azuma T, Yoshikawa T, Araida T, Takasaki K. Differential diagnosis of polypoid lesions of the gallbladder by endoscopic ultrasonography. Am J Surg 2001;181:65-70.

15. Sadamoto Y, Oda S, Tanaka M, Harada N, Kubo H, Eguchi T, et al. A useful approach to the differential diagnosis of small polypoid lesions of the gallbladder, utilizing an endoscopic ultrasound scoring system. Endoscopy 2002;34:959-65.

16. Kitano M, Kudo M, Yamao K, Takagi T, Sakamoto H, Komaki $\mathrm{T}$, et al. Characterization of small solid tumors in the pancreas: the value of contrast-enhanced harmonic endoscopic ultrasonography. Am J Gastroenterol 2012;107:303-10.

17. Kitano M, Sakamoto H, Matsui U, Ito Y, Maekawa K, von Schrenck T, et al. A novel perfusion imaging technique of the pancreas: contrast-enhanced harmonic EUS (with video). Gastrointest Endosc 2008;67:141-50.

18. Park CH, Chung MJ, Oh TG, Park JY, Bang S, Park SW, et al. Differential diagnosis between gallbladder adenomas and cholesterol polyps on contrast-enhanced harmonic endoscopic ultrasonography. Surg Endosc 2013;27:1414-21.

19. Choi JH, Seo DW, Choi JH, Park DH, Lee SS, Lee SK, et al. Utility of contrast-enhanced harmonic EUS in the diagnosis of malignant gallbladder polyps (with videos). Gastrointest Endosc 2013;78:484-93.

20. Golse N, Lewin M, Rode A, Sebagh M, Mabrut JY. Gallbladder adenomyomatosis: diagnosis and management. J Visc Surg 2017;154:345-53.

21. Gallahan WC, Conway JD. Diagnosis and management of gallbladder polyps. Gastroenterol Clin North Am 2010;39:35967. 
22. Shapiro RS, Winsberg F. Comet-tail artifact from cholesterol crystals: observations in the postlithotripsy gallbladder and an in vitro model. Radiology 1990;177:153-6.

23. Mellnick VM, Menias CO, Sandrasegaran K, Hara AK, Kielar AZ, Brunt EM, et al. Polypoid lesions of the gallbladder: disease spectrum with pathologic correlation. Radiographics 2015; 35:387-99.

24. Nishiyama Y, Yamamoto Y, Fukunaga K, Kimura N, Miki A, Sasakawa $Y$, et al. Dual-time-point 18F-FDG PET for the evaluation of gallbladder carcinoma. J Nucl Med 2006;47:633-8.

25. Zemour J, Marty M, Lapuyade B, Collet D, Chiche L. Gallbladder tumor and pseudotumor: diagnosis and management. J Visc Surg 2014;151:289-300.

26. Kim JH, Kim TK, Eun HW, Kim BS, Lee MG, Kim PN, et al. Preoperative evaluation of gallbladder carcinoma: efficacy of combined use of MR imaging, MR cholangiography, and contrast-enhanced dual-phase three-dimensional MR angiography. J Magn Reson Imaging 2002;16:676-84.

27. Xu A, Hu H. The gallbladder polypoid-lesions conundrum: moving forward with controversy by looking back. Expert Rev Gastroenterol Hepatol 2017;11:1071-80.

28. Limaiem F, Sassi A, Talbi G, Bouraoui S, Mzabi S. Routine histopathological study of cholecystectomy specimens. Useful? A retrospective study of 1960 cases. Acta Gastroenterol Belg 2017;80:365-70

29. Taskin OC, Bellolio E, Dursun N, Seven IE, Roa JC, Araya JC, et al. Non-neoplastic polyps of the gallbladder: a clinicopathologic analysis of 447 cases. Am J Surg Pathol 2020;44:467-76.

30. Xu A, Zhang Y, Hu H, Zhao G, Cai J, Huang A. Gallbladder polypoid-lesions: what are they and how should they be treated? A single-center experience based on 1446 cholecystectomy patients. J Gastrointest Surg 2017;21:1804-12.

31. Persley KM. Gallbladder polyps. Curr Treat Options Gastroenterol $2005 ; 8: 105-8$.

32. Haradome H, Ichikawa T, Sou H, Yoshikawa T, Nakamura A, Araki T, et al. The pearl necklace sign: an imaging sign of adenomyomatosis of the gallbladder at MR cholangiopancreatography. Radiology 2003;227:80-8.

33. Susumu S, Matsuo S, Tsutsumi R, Azuma T, Obata S, Hayashi T. Inflammatory polyp of the gallbladder mimicking early polypoid carcinoma. Case Rep Gastroenterol 2009;3:255-9.

34. Perez-Montiel D, Mucientes F, Spencer L, Klaassen R, Suster S. Polypoid leiomyosarcoma of the gallbladder: study of a case associated with adenomyomatous hyperplasia. Ann Diagn Pathol 2004;8:358-63.

35. Yang HL, Sun YG, Wang Z. Polypoid lesions of the gallbladder: diagnosis and indications for surgery. Br J Surg 1992;79:227-9.
36. Adsay NV. Neoplastic precursors of the gallbladder and extrahepatic biliary system. Gastroenterol Clin North Am 2007;36: 889-900.

37. Roa I, de Aretxabala X, Araya JC, Roa J. Preneoplastic lesions in gallbladder cancer.J Surg Oncol 2006;93:615-23.

38. Albores-Saavedra J, Chable-Montero F, Gonzalez-Romo MA, Ramirez Jaramillo M, Henson DE. Adenomas of the gallbladder: morphologic features, expression of gastric and intestinal mucins, and incidence of high-grade dysplasia/carcinoma in situ and invasive carcinoma. Hum Pathol 2012;43:1506-13.

39. Trivedi V, Gumaste VV, Liu S, Baum J. Gallbladder cancer: adenoma-carcinoma or dysplasia-carcinoma sequence? Gastroenterol Hepatol (NY) 2008;4:735-7.

40. Adsay V, Jang KT, Roa JC, Dursun N, Ohike N, Bagci P, et al. Intracholecystic papillary-tubular neoplasms (ICPN) of the gallbladder (neoplastic polyps, adenomas, and papillary neoplasms that are $\geq 1.0 \mathrm{~cm}$ ): clinicopathologic and immunohistochemical analysis of 123 cases. Am J Surg Pathol 2012;36:1279-301.

41. Kiruthiga KG, Kodiatte TA, Burad D, Kurian R, Raju RS, Rymbai ML, et al. Intracholecystic papillary-tubular neoplasms of the gallbladder: a clinicopathological study of 36 cases. Ann Diagn Pathol 2019;40:88-93.

42. Park JK, Yoon YB, Kim YT, Ryu JK, Yoon WJ, Lee SH, et al. Management strategies for gallbladder polyps: is it possible to predict malignant gallbladder polyps? Gut Liver 2008;2:88-94.

43. Lee J, Yun M, Kim KS, Lee JD, Kim CK. Risk stratification of gallbladder polyps $(1-2 \mathrm{~cm})$ for surgical intervention with 18 F-FDG PET/CT.J Nucl Med 2012;53:353-8.

44. Koh T, Taniguchi H, Yamaguchi A, Kunishima S, Yamagishi H. Differential diagnosis of gallbladder cancer using positron emission tomography with fluorine-18-labeled fluoro-deoxyglucose (FDG-PET).J Surg Oncol 2003;84:74-81.

45. Babu BI, Dennison AR, Garcea G. Management and diagnosis of gallbladder polyps: a systematic review. Langenbecks Arch Surg 2015;400:455-62.

46. Heitz L, Kratzer W, Grater T, Schmidberger J; EMIL study group. Gallbladder polyps: a follow-up study after 11 years. BMC Gastroenterol 2019; 19:42.

47. Colecchia A, Larocca A, Scaioli E, Bacchi-Reggiani ML, Di Biase AR, Azzaroli F, et al. Natural history of small gallbladder polyps is benign: evidence from a clinical and pathogenetic study. Am J Gastroenterol 2009;104:624-9.

48. Csendes A, Burgos AM, Csendes P, Smok G, Rojas J. Late follow-up of polypoid lesions of the gallbladder smaller than 10 mm. Ann Surg 2001;234:657-60.

49. Wiles R, Thoeni RF, Barbu ST, Vashist YK, Rafaelsen SR, Dewhurst C, et al. Management and follow-up of gallbladder pol- 
yps: joint guidelines between the European Society of Gastrointestinal and Abdominal Radiology (ESGAR), European Association for Endoscopic Surgery and other Interventional Techniques (EAES), International Society of Digestive Surgery-European Federation (EFISDS) and European Society of Gastrointestinal Endoscopy (ESGE). Eur Radiol 2017;27:3856-66.

50. Andren-Sandberg A. Diagnosis and management of gallbladder polyps. N Am J Med Sci 2012;4:203-11.

51. Myers RP, Shaffer EA, Beck PL. Gallbladder polyps: epidemiology, natural history and management. Can J Gastroenterol 2002;16:187-94.

52. Kwon W, Jang JY, Lee SE, Hwang DW, Kim SW. Clinicopathologic features of polypoid lesions of the gallbladder and risk factors of gallbladder cancer.J Korean Med Sci 2009;24:481-7.

53. Bhatt NR, Gillis A, Smoothey CO, Awan FN, Ridgway PF. Evidence based management of polyps of the gall bladder: a systematic review of the risk factors of malignancy. Surgeon 2016;14:278-86.

54. Cha BH, Hwang JH, Lee SH, Kim JE, Cho JY, Kim H, et al. Pre-operative factors that can predict neoplastic polypoid lesions of the gallbladder. World J Gastroenterol 2011;17:2216-
22.

55. Albores-Saavedra J, Vardaman CJ, Vuitch F. Non-neoplastic polypoid lesions and adenomas of the gallbladder. Pathol Annu 1993;28:145-77.

56. Aldouri AQ, Malik HZ, Waytt J, Khan S, Ranganathan K, Kummaraganti S, et al. The risk of gallbladder cancer from polyps in a large multiethnic series. Eur J Surg Oncol 2009;35:48-51.

57. European Association for the Study of the Liver. EASL Clinical Practice Guidelines: management of cholestatic liver diseases. J Hepatol 2009;51:237-67.

58. Said K, Glaumann H, Bergquist A. Gallbladder disease in patients with primary sclerosing cholangitis. J Hepatol 2008; 48:598-605.

59. van Erp LW, Cunningham M, Narasimman M, Ale Ali H, Jhaveri K, Drenth JP, et al. Risk of gallbladder cancer in patients with primary sclerosing cholangitis and radiographically detected gallbladder polyps. Liver Int 2020;40:382-92.

60. Torres C, Antonioli D, Odze RD. Polypoid dysplasia and adenomas in inflammatory bowel disease: a clinical, pathologic, and follow-up study of 89 polyps from 59 patients. Am J Surg Pathol 1998;22:275-84. 